\title{
Research on course quality evaluation index of higher vocational education
}

\author{
Wei Bao \\ Tianjin Maritime College, Tianjin, 300350, China \\ Email: baowei_tmc@163.com
}

\begin{abstract}
Keywords: Vocational education; practice teaching; evaluation index system; curriculum evaluation; indicator frame
\end{abstract}

\begin{abstract}
With the increasingly complex behavior of higher vocational education curriculum construction, higher vocational education curriculum quality evaluation is gradually separated from the teaching evaluation and academic evaluation and become an independent evaluation field. The construction of its evaluation index can be demand, structure, content, conditions and the implementation of these five elements as the basic framework. These five elements are independent of each other and have a strict intrinsic logical relationship, which is reflected in the quality of higher vocational education curriculum key elements. In order to improve the validity of evaluation, it is necessary to further confirm the key indicators which can reflect the quality of higher vocational education. The key of practice teaching in higher vocational colleges is to establish a scientific and reasonable evaluation index system of practical classroom teaching quality.
\end{abstract}

\section{Introduction}

Vocational training of a large number of high-skilled applied talents, has been in China's production, construction, service and management line play an increasingly important role [1, 2]. As the late start of higher vocational education in China, although the ministry of education has organized the conditions of higher vocational education, practice teaching base construction, vocational assessment of the implementation of professional activities, but practical teaching has not yet put forward a scientific evaluation index system and mature evaluation program [3]. Higher vocational colleges lack a systematic scientific evaluation index system of practical classroom teaching quality. Therefore, it is of great practical significance to set up a specific and objective evaluation system of classroom teaching quality in practice as soon as possible and become one of the problems that need to be solved urgently $[4,5]$.

An evaluation index is a specific evaluation item which is determined according to a certain evaluation objective and can reflect the essential characteristics of an aspect of the evaluation object. Indicators are specific, measurable, is the target observation point, through the actual observation of the object can get a clear conclusion [6-8]. The evaluation index system is an organic whole formed by the different levels of evaluation indicators according to the logical structure of the evaluation object itself. It is a measure system of the development level or status of educational evaluation objects, which is at the core of education evaluation. The evaluation index system is a systematic and closely linked set of indicators reflecting the whole evaluation object, which consists of evaluation index, index score and evaluation criteria.

Higher vocational education curriculum quality evaluation index system construction complexity is also obvious, because the index system:

(1)Must meet the validity of the evaluation requirements, that is able to objectively reflect a vocational college courses a professional quality level;

(2)Must be easy to operate, that is easy to collect on these indicators to judge the objective evidence;

(3)Must be relatively independent between indicators, that is, the indicators can not exist between the evaluation of cross-cutting content to avoid evaluation In the repeated scoring phenomenon. On the basis of fully considering these three issues, this paper will make a preliminary theoretical 
analysis on the construction of the evaluation index of curriculum quality in higher vocational education.

\section{Concept and characteristics of evaluation index system}

The practice teaching quality evaluation system of higher vocational education is an important guarantee to carry out the practice teaching management and realize the goal of personnel training. As far as possible, eliminate the influence of human factors, so that the practice of teaching evaluation index system, a system. The quality evaluation system of practice teaching in higher vocational education has the following characteristics:

Orientation is the evaluation system has the direction of the role of the evaluator. The evaluation index is decomposed by the evaluation objective, and the social value judgment made by the appraiser to the evaluated object is based on certain evaluation criteria.

Measurability is the final indicators in the evaluation indicators to be used to define the language can be manipulated, it provides the content can be measured directly, you can use it to collect the original data, information and other information in order to obtain a clear conclusion. If the decomposition of the secondary indicators can not be directly observed and observed, it can not serve as a final indicator, it must continue to break down. The key problem in determining the scope of curriculum evaluation lies in the fact that the curriculum concept must include the implementation of the curriculum, and the curriculum implementation is actually the intersecting area of curriculum, teaching and learning (Figure 1).

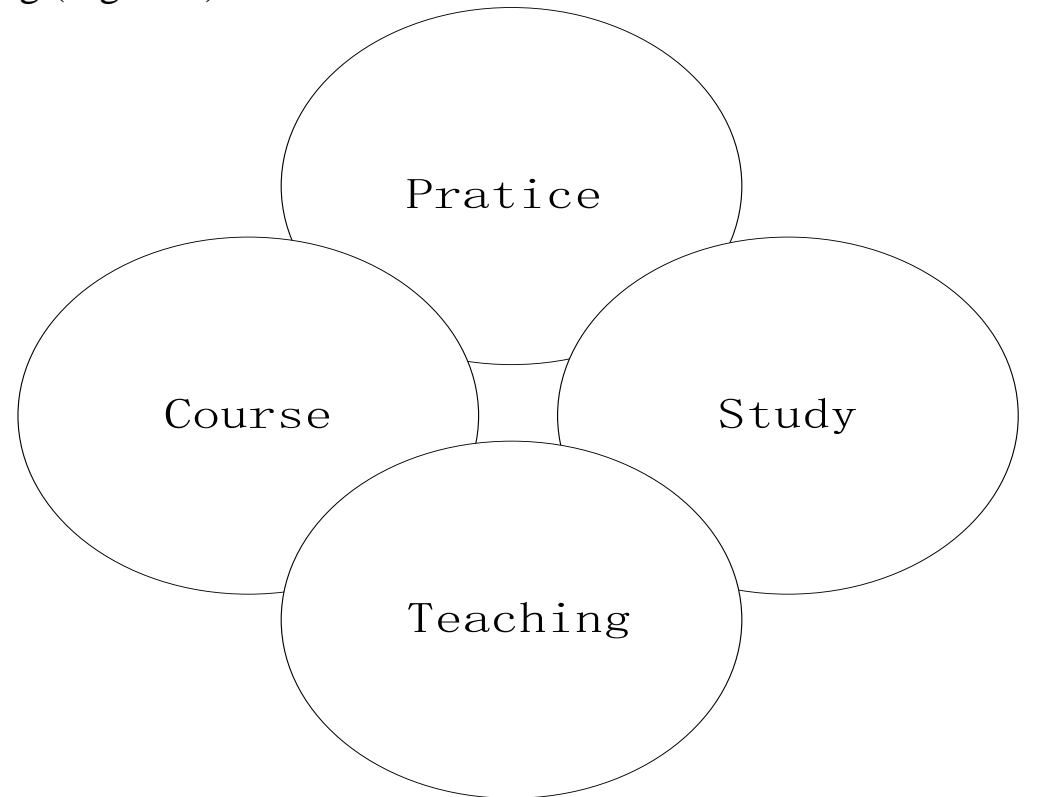

Figure 1. The relationship between curriculum, teaching and learning

It is easy to distinguish the curriculum evaluation from the teaching evaluation and the learning evaluation if we only focus on the static elements such as course objectives, curriculum, course content and course resources. The concept of the curriculum to understand the full content, but this evaluation is not conducive to vocational education to produce real courses. If we only focus on the assessment of the static curriculum elements, it is easy to lead to higher vocational education in the curriculum text construction and ignore the phenomenon of curriculum implementation.

\section{Practical classroom teaching quality evaluation index system table}

According to the content and characteristics of practical classroom teaching, we take 13 classes of secondary indexes and 39 observation points as the first-class indexes according to the practice of classroom teaching preparation, the practice of classroom teaching, and the fulfillment of classroom teaching. Practical classroom teaching quality evaluation system was shown in Table 1. 
Table 1. Practical classroom teaching quality evaluation index system table

\begin{tabular}{|c|c|c|c|}
\hline First level indicator & Secondary indicators & $\begin{array}{l}\text { Secondary indicators } \\
\text { of observation points }\end{array}$ & Score indicator \\
\hline \multirow{4}{*}{$\begin{array}{l}\text { Practice classroom } \\
\text { teaching situation }\end{array}$} & Teaching attitude & $\begin{array}{l}\text { Class time, do not } \\
\text { arbitrarily transfer, } \\
\text { suspension or } \\
\text { absence }\end{array}$ & 25 \\
\hline & Teaching organization & $\begin{array}{c}\text { Training } \\
\text { environment, } \\
\text { conditions are } \\
\text { available, fully } \\
\text { prepared }\end{array}$ & 25 \\
\hline & $\begin{array}{c}\text { Assessment and } \\
\text { evaluation }\end{array}$ & $\begin{array}{l}\text { Organization and } \\
\text { implementation of } \\
\text { training, focused, full } \\
\text { content }\end{array}$ & 25 \\
\hline & Teacher teaching site & $\begin{array}{l}\text { Training objectives, } \\
\text { requirements or } \\
\text { operational essentials } \\
\text { to express clearly }\end{array}$ & 25 \\
\hline
\end{tabular}

In the evaluation, feedback, improvement work is completed, the semester of the evaluation of the semester to do a good job in the new semester, according to the improved practice teaching methods for teaching activities, the college re-organization inspectors to conduct regular evaluation, and in each To ensure the integrity of the material, to provide the basis for the practice of teaching reform, to ensure that students achieve the goal of comprehensive vocational capacity, and promote the practice of classroom teaching in our hospital lasted for a period of time, each year on the practice of teaching quality evaluation file sorting, healthy growth.

\section{Five - factor model of curriculum evaluation in higher vocational education}

Based on the above analysis, combined with the observation of the practice of curriculum construction of higher vocational education, we can establish the five-factor model of curriculum evaluation of higher vocational education, namely, demand, structure, content, conditions and implementation of these five elements as the basic quality evaluation of higher vocational education Content, on the basis of further design of higher vocational education curriculum evaluation indicators (Figure 2).

(1) Demand refers to the level of the curriculum in the labor market needs (from the school point of view, perhaps more attention should be paid to the needs of students, but from the perspective of the social function of vocational education, or more attention should be paid to the labor market demand for courses), that is, after learning these courses the individual is likely to find the corresponding work, or find the possibility of the corresponding degree of work.

(2) Structure includes structure and content structure of the two aspects, the former refers to the combination between courses, which set the course, and what ideas to set these courses; the latter refers to a course within the content organization model, namely According to what logic to start a course content system.

(3) Content refers to the course to be taught, requires students to master the knowledge, skills and attitudes. 
(4) Conditions for the implementation of the curriculum required for all the supporting elements, including teachers, training equipment, curriculum resources, industry-university cooperation and other conditions.

(5) Implementation refers to the above-mentioned teaching and learning order and teachers and students of their respective roles in the state of input.

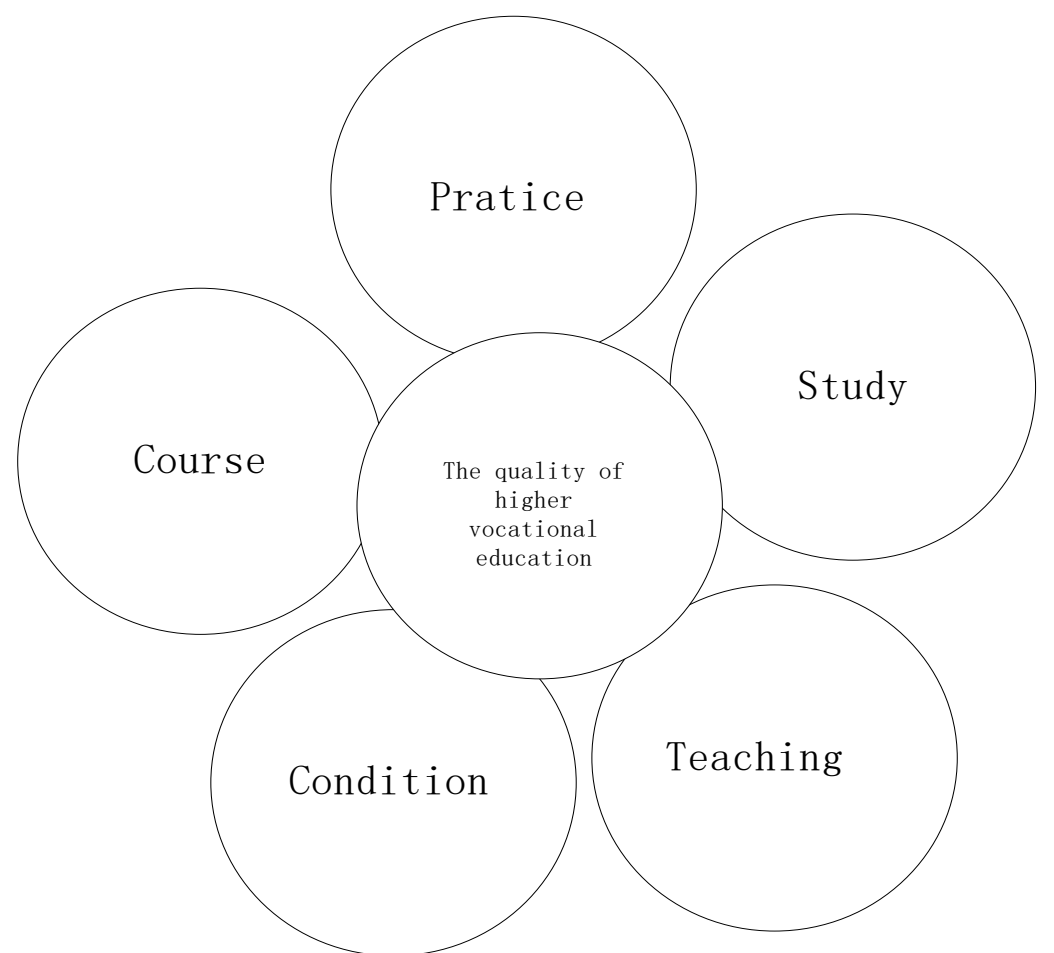

Figure 2. Five - factor model of curriculum evaluation in higher vocational education

\section{Summary}

This paper analyzes the current status and problems of classroom teaching quality evaluation in higher vocational education, and discusses the construction and implementation of evaluation index system of practice teaching quality in higher vocational education. With the increasingly complex behavior of higher vocational education curriculum construction, higher vocational education curriculum quality evaluation is gradually required to become an independent evaluation field from teaching evaluation and academic evaluation. This paper analyzes the curriculum of vocational education quality evaluation index is based on the assumption observations of practice in higher vocational education curriculum construction formed to develop vocational education curriculum quality assessment tool, the necessity to provide empirical data to establish the indicators.

\section{References}

[1] C.R.Dongarsane and A.N.Jadhav, "Simulation study on DOA estimation using MUSIC algorithm”, International Journal of Technology and Engineering System, vol.2, No.1, 2011, pp.54-57.

[2] Q. H. Spencer, A. L. Swindlehurst, M. Haardt. “Zero-Forcing Methods for Downlink Spatial Multiplexing in Multiuser MIMO Channel”, IEEE Transactions on Signal Processing, vol.52, no. 2, pp.461-471, May 2004.

[3] M. Sadek, A. Tarighat, A. H. Sayed, "A Leakage-based Precoding Scheme for Downlink multi-user MIMO Channels” , IEEE Transactions on Wireless Communications, vol. 26, no.8, pp.1505-1515, 2008. 
[4] A. Tarighat, M. Sadek, A. H. Sayed, “A multi User Beamforming Scheme for Downlink MIMO Channels based on Maximizing Signal-to-Leakage Ratios”, IEEE International Conference on Acoustics, Speech, and Signal Processing, pp. 1129-1132, 2005.

[5] J.van de Beek,O. Edfors, M. Sandell, S. Wilson, P. Borjesson, “On Channel Estimation in OFDM System”, in Proceedings of the IEEE Vehicular Technology Conference, pp. 815-819, 1995.

[6] K.Wong, R. Cheng, K. B. Letaeif, R. D. Murch, "Adaptive antennas at the mobile and base stations in an OFDM/TDMA system”, IEEE Transactions on Communications, vol. 49, no.1, pp. 195-206, 2001.

[7] M. Sadek, A. Tarighat, A. H. Sayed, "Active Antenna Selection in multi-user MIMO Communications,” IEEE Transactions on Signal Processing, vol. 55, no. 4, pp. 1498-1510, 2007.

[8] Krishnanand K N, Ghose D. Theoretical foundations for rendezvous of glowworm-inspired agent swarms at multiple locations [J]. Robotics and Autonomous Systems, 2008, 56(7): 549-569. 